\title{
Pipeline Flex Embolization of Flow-Related Aneurysms Associated with Arteriovenous Malformations: A Case Report
}

\author{
Narlin B. Beaty ${ }^{a}$ Jessica K. Campos ${ }^{a}$ Geoffrey P. Colby ${ }^{b} \quad$ Li-Mei Lin $^{c}$ \\ Matthew T. Bender ${ }^{a}$ Risheng $\mathrm{Xu}^{\mathrm{a}}$ Alexander L. Coon ${ }^{\mathrm{a}}$ \\ a Department of Neurosurgery, Johns Hopkins University School of Medicine, \\ Baltimore, MD, b Department of Neurosurgery, David Geffen School of Medicine at UCLA, \\ Los Angeles, CA, and ${ }^{C}$ Department of Neurosurgery, University of California, Irvine School \\ of Medicine, UC Irvine Medical Center, Orange, CA, USA
}

\section{Keywords}

Cerebral arteriovenous malformations - Endovascular management strategies - Flow diversion embolization · Flow-related aneurysm · Pipeline Flex Embolization Device

\begin{abstract}
Background: An estimated $0.1 \%$ of the population harbors brain arteriovenous malformations (AVMs). Diagnosis and workup of AVMs include thorough evaluation for characterization of AVM angioarchitecture and careful assessment for concomitant aneurysms. The presence of coexisting aneurysms is associated with an increased risk of intracranial hemorrhage, with a published risk of $7 \%$ per year compared to patients with AVMs alone with a risk of $3 \%$. Comprehensive AVM management requires recognition of concomitant aneurysms and prioritizes treatment strategies to mitigate the aggregate risk of intracranial hemorrhage associated with AVM rupture in patients with coexisting aneurysms. Endovascular treatment of these flow-related aneurysms can offer a cure, while avoiding open surgery. Successful flow-diverting embolization techniques, efficacy, and outcomes have been previously described for a variety of aneurysm types and locations. However, use of a flow diverter has not been previously described for the treatment of high-flow aneurysms on AVM-feeding vessels. Case Presentation: We report 2 cases of large AVMs within eloquent cortex associated with flow-related aneurysms in patients presenting initially with suspected intracerebral hemorrhage secondary to AVM rupture. Discussion: No consensus currently exists to guide treatment of intracranial aneurysms associated with AVMs. Surgical management addressed
\end{abstract}


AVM embolization initially, as the vasculopathology with the highest rupture risk. Subsequently, Pipeline embolization of the associated aneurysms with adequate antiplatelet treatment was performed before scheduled radiosurgery to decrease the risk of AVM rupture or rebleed. This represents a novel and promising use of the Pipeline Embolization Device. Additional cases and longer follow-up will be needed to further assess the efficacy of this technique.

(C) 2018 S. Karger AG, Basel

\section{Introduction}

An estimated $0.1 \%$ of the population harbors brain arteriovenous malformations (AVMs). Diagnosis and workup of AVMs include evaluation for characterization of AVM angioarchitecture and careful assessment for concomitant aneurysms [1-3]. Aneurysms in this patient population are categorized as intranidal, perinidal, flow-related, or unrelated to the AVM. Specifically, saccular and fusiform aneurysms arising along the direct course of arterial supply to the AVM are considered "flow-related" [4]. Coexisting aneurysms have been reported in up to $16.7 \%$ of cerebral AVMs [5-10]. The presence of coexisting unruptured aneurysms is associated with an increased risk of intracranial hemorrhage, with a published risk of $7 \%$ per year as compared to patients with AVMs alone with a risk of 3\% [5]. Comprehensive AVM management requires recognition of concurrent aneurysms and prioritizes treatment strategies to mitigate the aggregate risk of intracranial hemorrhage associated with AVM rupture in patients with coexisting aneurysms [4-12].

Flow diversion, using stents, such as the FDA-approved Pipeline Embolization Device (PED; Medtronic Neurovascular, Irvine, CA, USA), is a well-established endovascular treatment for cerebral aneurysms. Flow-diverting embolization techniques, efficacy, and outcomes have been previously described for a variety of aneurysm types and locations [13-16]. However, use of a flow diverter has not been previously described for the treatment of high-flow aneurysms on AVM-feeding vessels. Here, we present 2 cases of staged endovascular flow diversion of feeding vessel aneurysms followed by radiosurgery for AVM obliteration.

\section{Case Presentations}

Case 1

A 69-year-old African-American woman with a long-standing history of poorly controlled hypertension and 25 pack-years of smoking cigarettes presented with a "thunderclap" headache and blurred vision. While a head computed tomography (CT) demonstrated curvilinear sulcal hyperdensities in the right frontal lobe consistent with calcifications and not hemorrhage, a lumbar puncture was positive for xanthochromia. Magnetic resonance (MR) imaging/MR angiography and CT angiography demonstrated a right frontal AVM and associated aneurysms. Cerebral catheter angiography diagnosed a right frontal pre-motor SpetzlerMartin Grade IIIb AVM supplied by a hypertrophied frontal branch of the right anterior cerebral artery with superficial venous drainage via an enlarged cortical vein (Fig. 1). Two 6-mm right internal carotid artery ophthalmic segment aneurysms were also visualized and were not considered to be sources of the hemorrhage. A multi-staged, multi-modality treatment plan was made. This included initial Onyx (Medtronic Neurovascular) liquid embolization of the AVM, staged flow diversion of the associated aneurysms, and finally stereotactic radiosurgery of the AVM nidus.

The first stage of the endovascular treatment was Onyx embolization of the primary AVM-feeding vessels. This provided a 50\% reduction in arterial supply to the AVM nidus. The second stage of the endovascular treatment was planned Pipeline embolization of the high-flow aneurysms. A single Pipeline stent was positioned across the neck of both right internal carotid artery ophthalmic segment aneurysms and deployed without complications using techniques previously described [16-18]. Early follow-up angiography at 4 


\section{Interventional} Neurology

Fig. 1. Case 1: 69-year-old woman with 2 complex periophthalmic artery aneurysms. AP (a) and lateral (b) projections of ophthalmic ICA segment aneurysms in relation to the SM Grade IIIb AVM. AP (c) and lateral (d) projection of the PED Flex following deployment demonstrates apposition across the neck of the aneurysms. Four months later, AP (e) and lateral (f) projections show complete resolution of the distal ophthalmic ICA aneurysm, although there is still persistent filling of the proximal aneurysm. AP, anteroposterior; ICA, internal carotid artery; SM, Spetzler-Martin; AVM, arteriovenous malformation; PED, Pipeline Embolization Device.

\begin{tabular}{l|l}
\hline Intervent Neurol 2018;7:164-170 \\
\hline DOI: 10.1159/000484986 & $\begin{array}{l}\text { @ 2018 S. Karger AG, Basel } \\
\text { www.karger.com/ine }\end{array}$ \\
\hline
\end{tabular}

Beaty et al.: Pipeline Flex Embolization of Flow-Related Aneurysms Associated with Arteriovenous Malformations: A Case Report
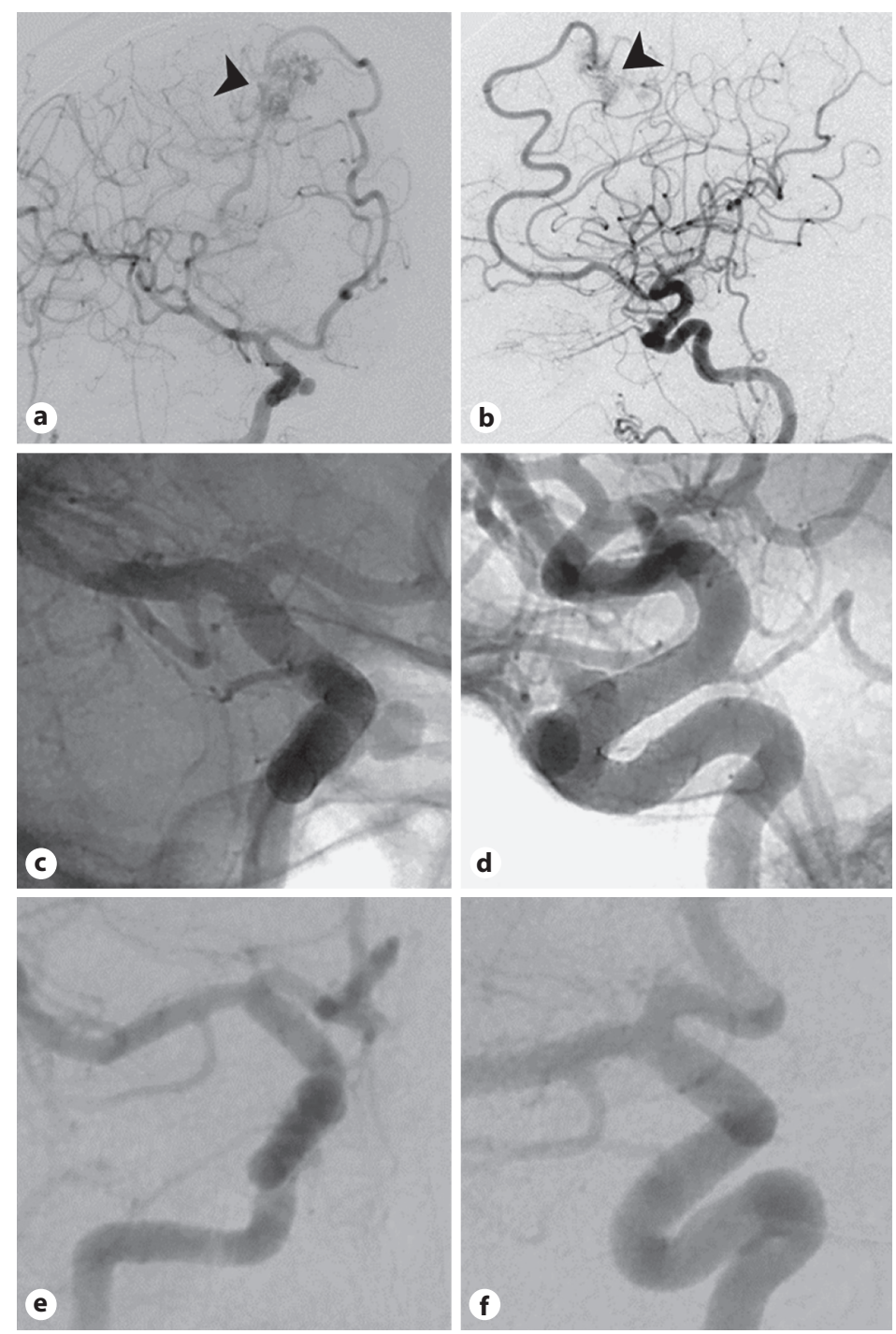

months demonstrated complete obliteration of the proximal aneurysm and significant reduction of flow to the more distal aneurysm (Fig. 1). The patient was subsequently scheduled for stereotactic radiosurgical ablation of the AVM.

\section{Case 2}

A 39-year-old woman presented with a large left temporoparietal intracerebral hemorrhage (5 cm). Her exam was notable for drowsiness, expressive aphasia, right-sided hemiplegia, and hyperreflexia. Cerebral catheter angiography demonstrated a Spetzler-Martin Grade IIIb 3.5-cm AVM located within the deep eloquent left parietotemporal area. Arterial supply originated from hypertrophied left middle cerebral artery and posterior cerebral artery feeders, and venous drainage was superficial through an enlarged temporal vein. A coexisting 6-mm flow-related left vertebral artery aneurysm was also diagnosed. The treatment plan included staged Onyx embolization followed by stereotactic radiosurgery and flow-diverting stent embolization for her vertebral aneurysm.

At the time of Onyx AVM intervention, a distal middle cerebral artery pedicle was embolized to successfully reduce flow within the nidus by $70 \%$. Six weeks later, the high-flow AVM-associated vertebral artery aneurysm was treated by Pipeline embolization (Fig. 2). Follow-up angiography demonstrated complete occlusion of the left vertebral artery aneurysm 12 months following Pipeline embolization, as seen in Figure 2. Following the embolization procedures, the patient was scheduled for definitive AVM treatment with stereotactic radiosurgery. 
Beaty et al.: Pipeline Flex Embolization of Flow-Related Aneurysms Associated with Arteriovenous Malformations: A Case Report

Fig. 2. Case 2: 41-year-old woman with a left temporal SM Grade IIIb AVM, as seen on the diagnostic cerebral catheter angiography. AP (a) and lateral (b) projections of a left vertebral artery fusiform aneurysm within the V4 segment. Immediately after placement of a Pipeline device (c), contrast stasis (d) can be seen. One year later, AP (e) and lateral (f) projections show complete angiographic resolution of the aneurysm. SM, Spetzler-Martin; AVM, arteriovenous malformation; AP, anteroposterior.
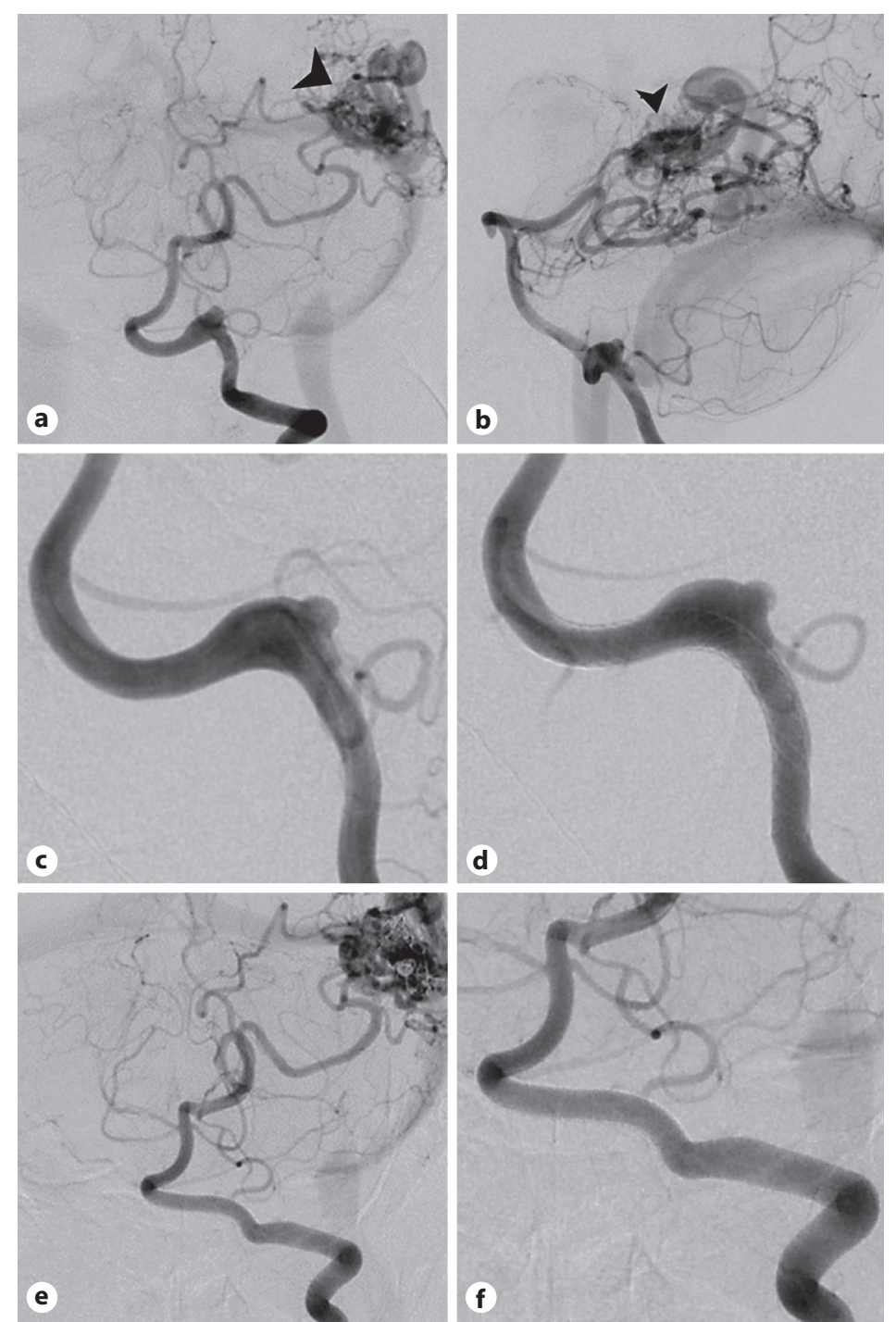

\section{Discussion}

Cerebral AVMs and coexisting intracranial aneurysms have been anecdotally discussed since 1942 [19]. Pathogenesis theories largely attribute the formation of AVM-associated aneurysms to pathological hemodynamics induced by the AVM, namely high proximal blood flow $[4,5,9,11]$. Shakur et al. [20] have since expanded this theory to emphasize the biomechanical importance of AVM feeder vessel wall shear stress in coexisting aneurysm development. No consensus currently exists to guide the treatment of intracranial aneurysms associated with AVMs. However, various case series discuss current treatment strategies for surgically managing AVMs with coexisting intracranial aneurysms [4-6, 9-11, 19, 21, 22]. Rammos et al. [22] suggest that the spatial relationship between the AVM nidus and the associated aneurysm, in addition to the patient's clinical presentation, should guide treatment decisions and timing.

Case report 1 described a clinical presentation concerning for acute intracranial hemorrhage, with CT and MR imaging demonstrating only a small amount of contrast enhancement near the AVM. The MR findings represented either a region of active vascular inflammation 
or a region of encephalomalacia from prior insult. The patient's initial presentation, coupled with the MR findings, necessitated expedient AVM treatment over treatment of the associated unruptured aneurysm for greater concern of AVM rupture [4-6, 9-11, 22]. Of note, the patient preferred endovascular treatment modalities. Initial treatment with AVM Onyx embolization was performed with 2 goals of therapy. The primary goal of reducing AVM size was achieved by reducing anterograde flow through AVM-feeding vessels. The secondary goal of AVM treatment, following concepts proposed by Redekop et al. [4], was to potentiate regression of the distal flow-related aneurysms [23]. On follow-up imaging, the aneurysm had not reduced in size. For this reason, Pipeline embolization was staged shortly thereafter.

Kano et al. [12] illustrated an increased risk of rebleeding following stereotactic radiosurgery in hemorrhagic AVMs with untreated associated aneurysms. The staging of treatment modalities must, therefore, be carefully evaluated. The surgical management of the highflow posterior temporal parietal AVM, outlined in case report 2, addressed AVM embolization initially as the vasculopathology with the highest rupture risk [4-6, 19, 24-27]. Subsequently, Pipeline embolization of the associated aneurysm with adequate antiplatelet treatment was performed before scheduled radiosurgery to decrease the risk of AVM rebleeding [12].

There is no current literature to guide antiplatelet or anticoagulation use in patients with recent AVM rupture [28-30]. The risk of rebleeding must be weighed against the benefits of aneurysm treatment by flow diversion, which requires dual antiplatelet medications to prevent platelet aggregation on the device. Other treatment modalities were considered, including surgery and coil embolization alone, or stent-coil embolization. These therapies were deemed inappropriate or less effective for the proximal, wide-necked aneurysms shown in Figures 1 and 2.

To our knowledge, flow diversion of AVM-feeding aneurysms has not previously been reported in the literature. This represents a novel and promising use of the PED. Additional cases and longer follow-up will be needed to further assess the efficacy of this technique.

\section{Statement of Ethics}

This research was approved by the Johns Hopkins institutional review board.

\section{Disclosure Statement}

A.L.C. is a proctor for the Woven EndoBridge device (Sequent Medical, Aliso Viejo, CA, USA), a proctor for the Surpass device (Stryker Neurovascular, Fremont, CA, USA) and a consultant for Stryker Neurovascular, a proctor for the Pipeline Embolization Device (Medtronic Neurovascular, Irvine, CA, USA) and a consultant for Medtronic Neurovascular, and a proctor for the FRED device (MicroVention-Terumo, Tustin, CA, USA) and a consultant for MicroVention. G.P.C. receives research support from Medtronic Neurovascular and Stryker Neurovascular and is a consultant for MicroVention-Terumo. L.-M.L. is a proctor for the Pipeline Embolization Device (Medtronic Neurovascular), a consultant for Medtronic Neurovascular, and a consultant for MicroVention-Terumo. The other authors have no conflicts of interest. No author received financial support in conjunction with the generation of this submission. 


\begin{tabular}{l|l}
\hline DOI: $10.1159 / 000484986$ & $\begin{array}{l}\text { @ } 2018 \text { S. Karger AG, Basel } \\
\text { www.karger.com/ine }\end{array}$ \\
\hline
\end{tabular}

Beaty et al.: Pipeline Flex Embolization of Flow-Related Aneurysms Associated with Arteriovenous Malformations: A Case Report

\section{References}

1 Spetzler RF, Martin NA: A proposed grading system for arteriovenous malformations. J Neurosurg 1986;65: 476-483.

2 Brown RD Jr, Wiebers DO, Torner JC, O’Fallon WM: Frequency of intracranial hemorrhage as a presenting symptom and subtype analysis: a population-based study of intracranial vascular malformations in Olmsted Country, Minnesota. J Neurosurg 1996;85:29-32.

3 Davies JM, Kim H, Young WL, Lawton MT: Classification schemes for arteriovenous malformations. Neurosurg Clin N Am 2012;23:43-53.

4 Redekop G, TerBrugge K, Montanera W, Willinsky R: Arterial aneurysms associated with cerebral arteriovenous malformations: classification, incidence, and risk of hemorrhage. J Neurosurg 1998;89:539-546.

5 Brown RD Jr, Wiebers DO, Forbes GS: Unruptured intracranial aneurysms and arteriovenous malformations: frequency of intracranial hemorrhage and relationship of lesions. J Neurosurg 1990;73:859-863.

6 Stapf C, Mohr JP, Pile-Spellman J, Sciacca RR, Hartmann A, Schumacher HC, Mast H: Concurrent arterial aneurysms in brain arteriovenous malformations with haemorrhagic presentation. J Neurol Neurosurg Psychiatry 2002;73:294-298.

7 da Costa L, Thines L, Dehdashti AR, Wallace MC, Willinsky RA, Tymianski M, Schwartz ML, ter Brugge KG: Management and clinical outcome of posterior fossa arteriovenous malformations: report on a single-centre 15-year experience. J Neurol Neurosurg Psychiatry 2009;80:376-379.

8 Abla AA, Nelson J, Rutledge WC, Young WL, Kim H, Lawton MT: The natural history of AVM hemorrhage in the posterior fossa: comparison of hematoma volumes and neurological outcomes in patients with ruptured infraand supratentorial AVMs. Neurosurg Focus 2014;37:E6.

9 Platz J, Berkefeld J, Singer OC, Wolff R, Seifert V, Konczalla J, Güresir E: Frequency, risk of hemorrhage and treatment considerations for cerebral arteriovenous malformations with associated aneurysms. Acta Neurochir (Wien) 2014;156:2025-2034.

10 Jha V, Behari S, Jaiswal AK, Bhaisora KS, Shende YP, Phadke RV: The "focus on aneurysm” principle: classification and surgical principles of management of concurrent arterial aneurysm with arteriovenous malformation causing intracranial hemorrhage. Asian J Neurosurg 2016;11:240-254.

11 Thompson RC, Steinberg GK, Levy RP, Marks MP: The management of patients with arteriovenous malformations and associated intracranial aneurysms. Neurosurgery 1998;43:202-211; discussion 211-212.

12 Kano H, Kondziolka D, Flickinger JC, Yang HC, Park KJ, Flannery TJ, Liu X, Niranjan A, Lunsford LD: Aneurysms increase the risk of rebleeding after stereotactic radiosurgery for hemorrhagic arteriovenous malformations. Stroke 2012;43:2586-2591.

13 Fiorella D, Woo HH, Albuquerque FC, Nelson PK: Definitive reconstruction of circumferential, fusiform intracranial aneurysms with the Pipeline embolization device. Neurosurgery 2008;62:1115-1120; discussion 1120-1121.

14 Lylyk P, Miranda C, Ceratto R, Ferrario A, Scrivano E, Luna HR, Berez AL, Tran Q, Nelson PK, Fiorella D: Curative endovascular reconstruction of cerebral aneurysms with the Pipeline Embolization Device: the Buenos Aires experience. Neurosurgery 2009;64:632-642; discussion 642-643; quiz N636.

15 Becske T, Brinjikji W, Potts MB, Kallmes DF, Shapiro M, Moran CJ, Levy EI, McDougall CG, Szikora I, Lanzino G, Woo HH, Lopes DK, Siddiqui AH, Albuquerque FC, Fiorella DJ, Saatci I, Cekirge SH, Berez AL, Cher DJ, Berentei Z, Marosfoi M, Nelson PK: Long-Term clinical and angiographic outcomes following Pipeline Embolization Device treatment of complex internal carotid artery aneurysms: five-year results of the Pipeline for Uncoilable or Failed Aneurysms Trial. Neurosurgery 2017;80:40-48.

16 Colby GP, Lin LM, Caplan JM, Jiang B, Huang J, Tamargo RJ, Coon AL: Immediate procedural outcomes in 44 consecutive Pipeline Flex cases: the first North American single-center series. J Neurointerv Surg 2016;8: 702-709.

17 Lin LM, Colby GP, Huang J, Tamargo RJ, Coon AL: Ultra-distal large-bore intracranial access using the hyperflexible Navien distal intracranial catheter for the treatment of cerebrovascular pathologies: a technical note. J Neurointerv Surg 2014;6:301-307.

18 Colby GP, Lin LM, Huang J, Tamargo RJ, Coon AL: Utilization of the Navien distal intracranial catheter in 78 cases of anterior circulation aneurysm treatment with the Pipeline embolization device. J Neurointerv Surg 2013;5(suppl 3):iii16-iii21.

19 Ding D, Xu Z, Starke RM, Yen CP, Shih HH, Buell TJ, Sheehan JP: Radiosurgery for cerebral arteriovenous malformations with associated arterial aneurysms. World Neurosurg 2016;87:77-90.

20 Shakur SF, Amin-Hanjani S, Mostafa H, Charbel FT, Alaraj A: Hemodynamic characteristics of cerebral arteriovenous malformation feeder vessels with and without aneurysms. Stroke 2015;46:1997-1999.

21 Walsh FB, King AB: Ocular signs of intracranial saccular aneurysms: experimental work on collateral circulation through the ophthalmic artery. Arch Ophthalmol 1942;27:1-33.

22 Rammos SK, Gardenghi B, Bortolotti C, Cloft HJ, Lanzino G: Aneurysms associated with brain arteriovenous malformations. AJNR Am J Neuroradiol 2016, DOI: 10.3174/ajnr.A4869.

23 Gross BA, Du R: Natural history of cerebral arteriovenous malformations: a meta-analysis. J Neurosurg 2013; 118:437-443.

24 Lawton MT, Kim H, McCulloch CE, Mikhak B, Young WL: A supplementary grading scale for selecting patients with brain arteriovenous malformations for surgery. Neurosurgery 2010;66:702-713. 
25 Appelboom G, Hwang BY, Bruce SS, Piazza MA, Kellner CP, Meyers PM, Connolly ES: Predicting outcome after arteriovenous malformation-associated intracerebral hemorrhage with the original ICH score. World Neurosurg 2012;78:646-650.

26 Neidert MC, Lawton MT, Mader M, Seifert B, Valavanis A, Regli L, Bozinov O, Burkhardt JK: The AVICH score: a novel grading system to predict clinical outcome in arteriovenous malformation-related intracerebral hemorrhage. World Neurosurg 2016;92:292-297.

27 Gaab MR: Intracerebral hemorrhages from cerebral arteriovenous malformations: prognostic grading. World Neurosurg 2016;93:471-473.

28 Al-Shahi Salman R, Dennis MS: Antiplatelet therapy may be continued after intracerebral hemorrhage. Stroke 2014;45:3149-3150.

29 Flynn RW, MacDonald TM, Murray GD, MacWalter RS, Doney AS: Prescribing antiplatelet medicine and subsequent events after intracerebral hemorrhage. Stroke 2010;41:2606-2611.

30 Pasquini M, Charidimou A, van Asch CJ, Baharoglu MI, Samarasekera N, Werring DJ, Klijn CJ, Roos YB, Al-Shahi Salman R, Cordonnier C: Variation in restarting antithrombotic drugs at hospital discharge after intracerebral hemorrhage. Stroke 2014;45:2643-2648. 